\title{
ANÁLISE PROSÓDICA DIALETAL DO PORTUGUÊS FALADO EM BELÉM (PA) COM DADOS AMPER
}

\author{
Brayna Conceição dos Santos Cardoso ${ }^{1}$ \\ Regina Célia Fernandes $\mathrm{Cruz}^{2}$ \\ Camila Roberta dos Santos Brito ${ }^{3}$
}

\begin{abstract}
RESUMO
A pesquisa apresenta resultados de um estudo acústico sobre a variação prosódica dialetal do português falado em Belém do Pará. Trata-se de uma análise da variação entoacional de sentenças declarativas e interrogativas com base nos dados AMPER. Para constituir o corpus, selecionamos 21 frases, nas 2 modalidades entoacionais, de 6 locutores nativos, estratificados em sexo e escolaridade. Utilizamos os arquivos AMPER contendo as medidas acústicas das 3 melhores repetições de cada frase; totalizando 756 dados analisados. Os valores de F0 foram estilizados no Prosogram, utilizaramse valores de duração relativa das unidades $\mathrm{V} 2 \mathrm{~V}$, em seguida a duração e a intensidade de cada locutor foram normalizadas em $\mathrm{z}$-score. A análise comprova que, para F0, a curva melódica no final do enunciado apresenta movimento descendente para as sentenças declarativas e ascendente para as interrogativas; quanto à duração, o contorno final circunflexo previsto por Moraes (1998) para o PB é observado na variedade.
\end{abstract}

Palavras-chave: Análise Acústica. Variedade Belenense. AMPER.

\begin{abstract}
The research presents the results of an acoustic study of the prosodic dialectal variation of the Portuguese spoken in Belém. It is an analysis of intonational variation of declarative and interrogative sentences based on AMPER data. To form the corpus, we selected 21 sentences, the intonation 2 modes of 6 native speakers, stratified by sex and education. We use AMPER files containing the acoustic measurements of the three best repetitions of each sentence; totaling 756 analyzed data. F0 values have been stylized in Prosogram, they used the relative duration values V2V units, then the duration and intensity of each speaker were normalized z-score. The analysis shows that, for F0, the melodic curve at the end of the statement shows downward movement for declarative sentences and up to the interrogative; for duration, the final contour caret provided by Moraes (1998) for the PB is observed on the variety.
\end{abstract}

Keywords: Acoustic Analysis. Variety Belenense. AMPER.

Recebido em: 21/04/ 2017

Aprovado em: 10/05/2017

\section{INTRODUÇÃO}

O presente estudo analisa a variação prosódica dialetal do português falado em Belém

\footnotetext{
1 Doutoranda do Programa de Pós-Graduação em Letras da Universidade Federal do Pará. E-mail: brayna.cardoso@gmail.com.

2 Professora do Instituto de Letras e Comunicação da Universidade Federal do Pará e Bolsista Produtividade do CNPq. E-mail: regina@ufpa.br.

${ }^{3}$ Graduada em Letras/Língua Portuguesa pela Universidade Federal do Pará. E-mail: letcamila89@gmail.com.
} 
do Pará. Trata-se de um trabalho de natureza prosódica, baseado nas premissas da Fonética Acústica, seguindo os moldes preconizados pelo Projeto AMPER.

A produção deste estudo justifica-se pelo interesse em estabelecer as características prosódicas pertinentes dos contornos entoacionais, permitindo identificar as características prosódicas marcadas na variedade linguística falada na capital belenense.

Para tanto, objetivamos identificar os parâmetros prosódicos pertinentes associados com a oposição entre as modalidades entoacionais declarativa e interrogativa; verificar o comportamento prosódico particular na produção de ambas as modalidades entoacionais alvo e destacar as variações significativas do padrão melódico da variedade em escopo.

Dessa forma, o estudo acústico analisa a variação entoacional de sentenças declarativas e interrogativas proferidas pelos participantes da pesquisa (6 falantes nativos de Belém), a fim de caracterizar o padrão físico da fala belenense, por meio dos parâmetros de frequência fundamental (F0), intensidade e duração.

Como forma de esboçar um panorama geral do que será exposto, este artigo é estruturado em quatro seções, nas quais são abordadas os seguintes conteúdos: a primeira seção apresenta o projeto AMPER e a sua trajetória de trabalho; a segunda seção abarca a revisão da literatura, tratando dos aspectos inerentes à Prosódia e a Fonética Acústica; a terceira seção descreve os percursos metodológicos da pesquisa, apresentando o contexto da pesquisa, a estratificação social dos participantes da pesquisa e o tratamento dos dados; a quarta seção apresenta a análise dos dados.

As reflexões resultantes da pesquisa culminam nas considerações finais aqui tecidas, comprovando que, para F0, a curva melódica no final do enunciado apresenta movimento descendente para as sentenças declarativas e ascendente para as interrogativas; quanto à duração, o contorno final circunflexo previsto por Moraes (1998) para o PB é observado na variedade. Em seguida, apresentam-se as Referências, que embasam o estudo realizado.

\section{O PROJETO AMPER}

O projeto AMPER, coordenado por Michel Contini, sediado na Universidade de Grenoble Alpes, foi criado com objetivo de estudar a organização prosódica das variedades linguísticas faladas no espaço dialetal românico.

A pesquisa inerente à variação prosódica do português é coordenada por Lurdes de Castro Moutinho, no Centro de Investigação de Línguas e Cultura da Universidade de Aveiro. O estudo da variação prosódica da língua portuguesa visa contribuir significativamente com o 
conhecimento dessa variedade e, também, a disponibilização de um corpus online, a fim de possibilitar futuras investigações em diversos níveis de análise linguística.

No Brasil, várias universidades federais são colaboradoras do projeto AMPER-POR, dentre elas, destaca-se a Universidade Federal do Pará, unidade que sedia o Projeto AMPERNorte, coordenado por Regina Célia Fernandes Cruz. O projeto AMPER-Norte tem investigado de forma intensiva a variação dialetal do português falado no norte do Brasil, especialmente no estado do Pará, em uma perspectiva prosódica. O AMPER-Norte é responsável por cinquenta por cento do volume de dados do português brasileiro já repassado ao projeto AMPER-POR, para compor a base de dados do Atlas Multimédia Prosódico do Português. A seguir apresentamos o organograma de pesquisa que o projeto AMPER compreende:

Figura 1: Organograma do Projeto AMPER nos países românicos e localidades de investigação do AMPER-POR

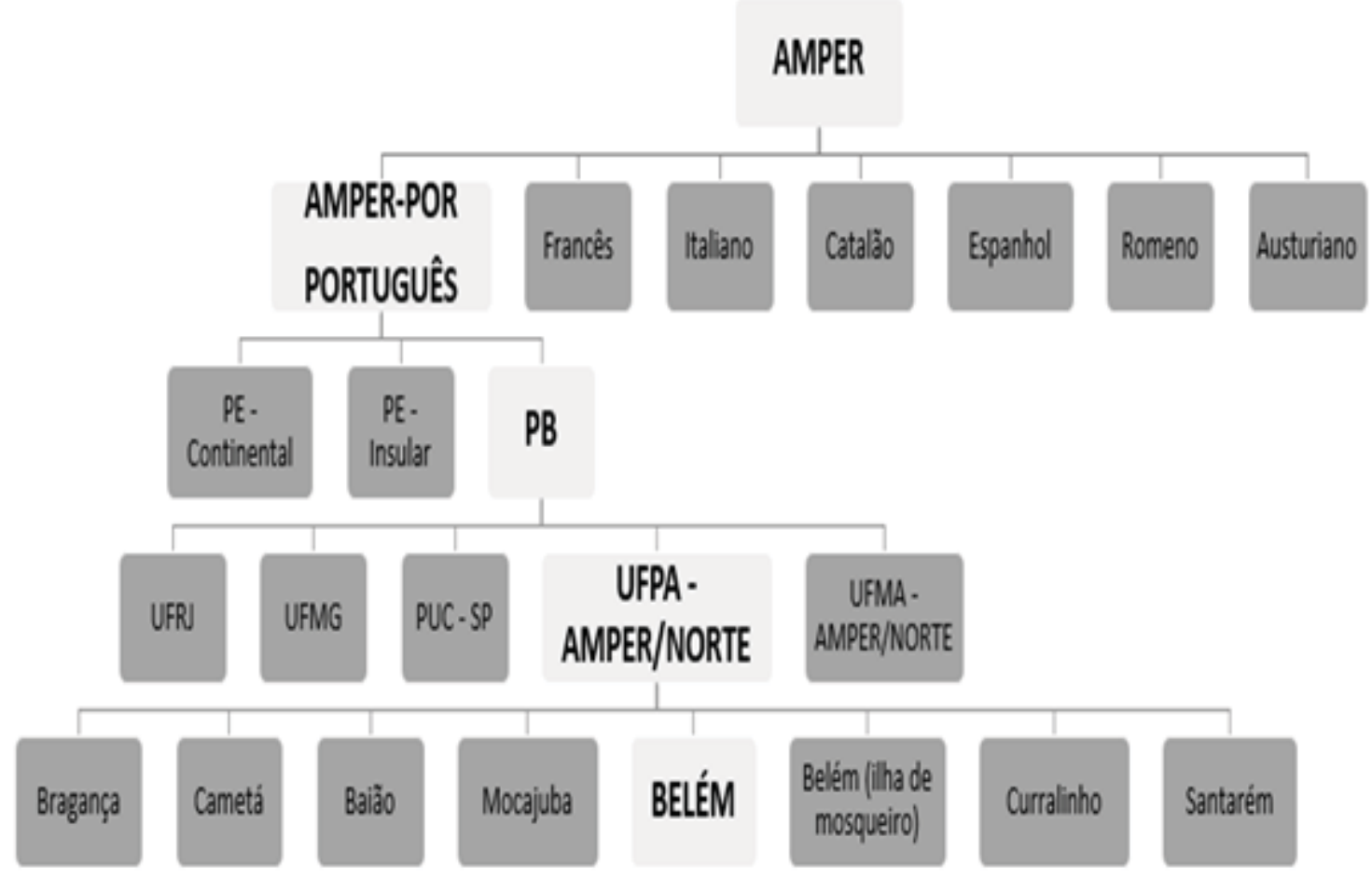

Fonte: Adaptado de Santo (2012).

No sentido de viabilizar pesquisas dialetais comparáveis para todas as línguas românicas, o projeto adota uma mesma estratégia de inquérito, o mesmo procedimento de análise instrumental multiparamétrico, um questionário comum de base (QCB) composto de sentenças a serem produzidas em duas modalidades entoacionais (declarativa e interrogativa 
total).

O corpus obtido pelo projeto AMPER não permite somente análise dialetal clássica, mas também análise sociolinguística graças as variáveis contempladas no projeto, a saber: idade, sexo e escolaridade.

O projeto AMPER possui também instrumentos de análise acústica e representação gráfica comuns a todas as línguas alvo do projeto e suas variedades. Para a análise acústica, o projeto AMPER dispõe de dois softwares: a) MatLab com scripts criado por Antonio Romano (1999); b) PRAAT com textgrid criado por Albert Rilliard (2008). Para a elaboração dos gráficos, Alexandre Vieira (UA) criou uma folha Excel como template (1999), o grupo da UFPA utiliza a Interface AMPER criada por Albert Rilliard (2008).

\section{A PROSÓdIA E A FONÉTICA ACÚSTICA}

O quadro teórico desta pesquisa concentra-se nos estudos inerentes a prosódia tomando como base a Fonética Acústica, com a utilização de dados sociolinguísticos induzidos. Tais ciências estudam a fala, procedendo ao seu recorte de acordo com os modelos teóricos e métodos de análises específicos adotados.

Para Barbosa; Madureira (2015), a análise acústica da fala pode ser feita tanto no eixo sintagmático quanto no eixo paradigmático, a pesquisa aqui empreendida insere-se no primeiro eixo, tratando da comparação de segmentos acústicos distintos de um enunciado, com vistas aos aspectos prosódicos.

Cabe à prosódia o estudo da coordenação da sequência dos gestos articulatórios ao longo dos enunciados. A prosódia molda a enunciação caracterizando o que se fala, o modo de falar dirigido intencionalmente ou não ao ouvinte.

Segundo Roach (2002), a prosódia é a adição de traços suprassegmentais da fala aos sons. Vários aspectos da fala, como entonação, melodia, ritmo, acento, podem ser investigados levando-se em conta os traços prosódicos. Estes traços são definidos em parâmetros acústicos de frequência fundamental (F0), intensidade e duração.

A frequência fundamental (F0) é relativa a vibração das pregas vocais, dependendo da espessura dessas pregas, quanto mais espessa, mais lenta a sua vibração. A unidade física da frequência é expressa em Hertz (Hz). Com efeito, Kent; Read (2015, p.134) afirmam que a frequência fundamental é um “dos maiores padrões (períodos mais longos) [...] resultam de vibrações das pregas vocais e correspondem à frequência que percebemos como um tom vocal (pitch); à medida que esses padrões se tornam mais frequentes, o tom percebido aumenta". A 
frequência fundamental é contributo primário para a sensação de altura (pitch), isto é, a sensação de que um som é mais ou menos grave ou mais ou menos agudo.

Sendo a F0 e, consequentemente o pitch, muito importantes para a descrição prosódica, a pesquisa fonética se dedica aos desdobramentos desses parâmetros em busca de pistas que revelem fenômenos dialetais, linguísticos ou paralinguísticos. A variação de F0, seja em um movimento específico interno à vogal, seja do enunciado é um parâmetro adotado para a descrição de diferenças de significados, inclusive de curvas atitudinais.

A intensidade depende da pressão de saída de ar dos pulmões, quanto maior a força expiatória, maior será a intensidade. A unidade física da intensidade é expressa em decibéis (dB). Barbosa; Madureira (2015, p.57) atestam que "a intensidade sonora é proporcional ao quadrado da amplitude de pressão sonora [...] a relação entre elas é monotônica". As medidas de intensidade e amplitude são diretamente proporcionais, quando uma medida aumenta ou diminui a outra também aumenta ou diminui.

A variação da intensidade acústica demonstra quando um tom é mais suave ou mais forte, e a associa aos elementos de duração e variação melódica, marcando a saliência da sílaba tônica. Vale ressaltar, que o ouvido humano não é tão sensível às diferenças de intensidade quanto é aguçado para identificar a frequência.

A duração refere-se ao tempo de articulação de um som ou enunciado, depende da duração os aspectos relacionados a velocidade da fala, a qualidade (característica dos traços) do segmento de fala e de como se dá o encadeamento das unidades menores. A unidade física da duração é expressa em milissegundo (ms).

Barbosa; Madureira (2015, p.69) tecem suas considerações acerca da duração demonstrando que "não é uma propriedade da onda, mas uma medida de tempo transcorrido entre dois eventos singulares que precisam estar, de alguma forma, ligados em nossa memória operacional para que percebamos a duração entre os eventos". Nesse sentido, o arranjo do continuum da fala faz com que todos os elementos de duração se tornem variáveis, interagindo entre si e fazendo com que esse parâmetro seja tomado, preferencialmente, como um valor relativo.

As modalidades entoacionais são caracterizadas de acordo com o desenho da curva melódica apresentada nos enunciados. Neste trabalho, a pesquisa se detém às modalidades declarativas neutras e interrogativas totais, as quais diferenciam-se a partir de um movimento de ascensão e decaimento. A distinção entre as interrogativas e declarativas são encontradas na parte final dos enunciados, visto que as interrogativas apresentam movimento de ascensão e decaimento e as declarativas pela ausência de ascensão. Vale destacar, há outros elementos 
que corroboram para a identificação de um enunciado declarativo ou interrogativo, todavia, a característica entoacional é a mais evidente.

No que concerne as modalidades entoacionais, Ladd (1996) afirma que a entonação é uma forte marca de caracterização de uma variedade de fala, pois proporciona reconhecer a melodia de uma dada região, visto que o falante é sensibilizado primeiramente pelas nuances que apresenta a camada fônica do falar de seu interlocutor.

A utilização de dados sociolinguísticos é concernente a relação dos estudos entre língua e sociedade, pois como preconiza Calvet (2002, p.12), “as línguas não existem sem as pessoas que as falam, e a história de uma língua é a história de seus falantes". O ser humano tem o poder de refletir e agir sobre o sistema da língua tanto de forma consciente como inconsciente, imprimindo as características socioculturais que permeiam a história de sua língua.

A variação linguística é o objeto de estudo da Sociolinguística, este método propõe uma visão de língua como um sistema heterogêneo e plural, desse modo à língua se apresenta de diversas formas a depender do uso feito pela comunidade linguística. As variações que ocorrem na língua são relacionadas a fatores linguísticos e extralinguísticos diversos, podendo ocorrer entre uma mesma comunidade de fala ou em comunidades diferentes. Em nível extralinguístico, as variações produzidas levam em conta fatores diatópicos, diastráticos, diafásicos e diassexuais. Assim, o fato de pertencer a uma determinada região, pertencer a uma classe social e falar de certo modo demonstra a variação presente na língua.

\section{METODOLOGIA DA PESQUISA: O CONTEXTO DA PESQUISA, A ESTRATIFICAÇÃO SOCIAL DOS PARTICIPANTES DA PESQUISA E TRATAMENTO DOS DADOS}

Este estudo tem o propósito de analisar a variação prosódica dialetal do português falado em Belém (PA), por meio dos parâmetros acústicos de F0, duração e intensidade, nas sentenças declarativas neutras e interrogativas totais, a fim de demonstrar o padrão entoacional que caracteriza a fala do belenense.

A estratificação social da pesquisa consiste na seleção de seis locutores, três locutores do sexo masculino e três locutores do sexo feminino, nativos de Belém (PA), com faixa etária acima de trinta anos e nível de escolaridade alto (ensino superior), médio (ensino médio) e baixo (ensino fundamental). A estratificação social segue a metodologia empreendida no projeto AMPER, codificando os participantes da pesquisa do seguinte modo: 
Quadro 1: Codificação e estratificação social dos participantes da pesquisa

\begin{tabular}{|c|c|c|c|c|}
\hline Localidade & Codificação & Sexo & Escolaridade & Faixa Etária \\
\hline \multirow{4}{*}{ Belém } & BE01 & Masculino & Ensino Fundamental & acima de 30 anos \\
\cline { 2 - 5 } & BE02 & Feminino & Ensino Fundamental & acima de 30 anos \\
\cline { 2 - 5 } & BE03 & Masculino & Ensino Médio & acima de 30 anos \\
\cline { 2 - 5 } & BE04 & Feminino & Ensino Médio & acima de 30 anos \\
\cline { 2 - 5 } & BE05 & Masculino & Ensino Superior & acima de 30 anos \\
\cline { 2 - 5 } & BE06 & Feminino & Ensino Superior & acima de 30 anos \\
\hline
\end{tabular}

Para garantir a espontaneidade da fala, a gravação ocorreu em um ambiente escolhido pelo informante. Utilizamos como estímulo visual slides, apresentados no programa Power Point, os slides continham os elementos formadores das sentenças, o informante visualizava os elementos e por um processo de indução formava as sentenças representadas pelas figuras, como podemos observar na figura a seguir: 
Fig. 2: Sentenças declarativa e interrogativa do corpus AMPER
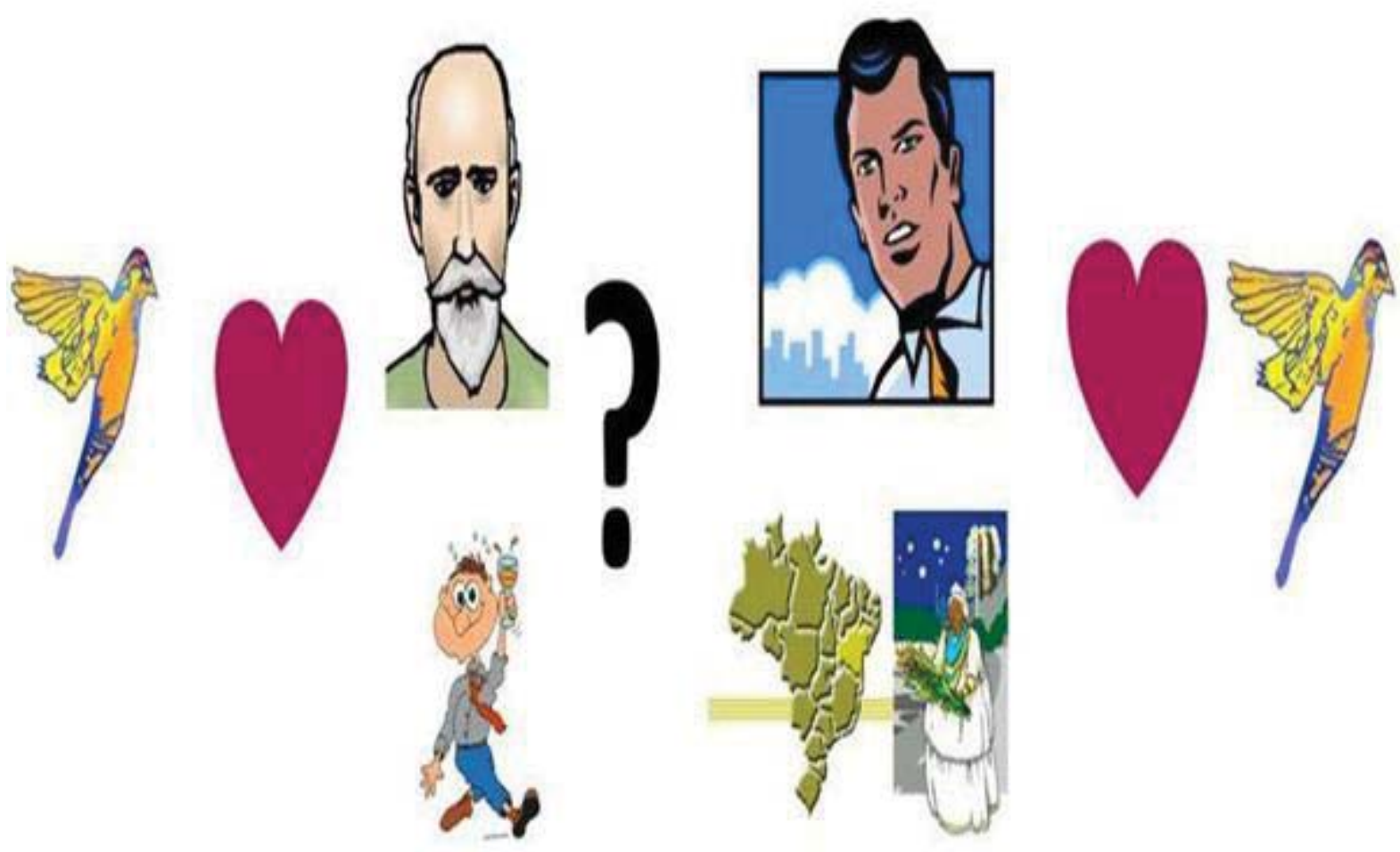

Legenda: Sentença 1 - O pássaro gosta do bisavô pateta? (sentença interrogativa) e Sentença 2 - Renato de Salvador gosta do pássaro (sentença declarativa).

A fim de uma observação mais detalhada, apresentamos o quadro com as 21 frases do corpus AMPER, produzidas nas modalidades entoacionais declarativa neutra e interrogativa total, componentes do questionário comum de base (QCB), principal instrumento para a composição do corpus de Belém (PA). 
Quadro 2: Corpus AMPER

\begin{tabular}{|c|c|c|c|}
\hline $\begin{array}{c}\text { Sintagma } \\
\text { Final }\end{array}$ & $\begin{array}{c}\text { Padrão Acentual } \\
\text { Proparoxítono }\end{array}$ & $\begin{array}{c}\text { Padrão Acentual } \\
\text { Paroxítono }\end{array}$ & $\begin{array}{c}\text { Padrão Acentual } \\
\text { Oxítono }\end{array}$ \\
\hline SN & $\begin{array}{c}\text { O pássaro gosta do } \\
\text { pássaro }\end{array}$ & $\begin{array}{c}\text { O Renato gosta do } \\
\text { Renato }\end{array}$ & $\begin{array}{c}\text { O bisavô gosta do } \\
\text { bisavô }\end{array}$ \\
\hline SN & $\begin{array}{c}\text { O Renato gosta do } \\
\text { pássaro }\end{array}$ & O bisavô gosta do Renato & $\begin{array}{c}\text { O Renato gosta do } \\
\text { bisavô }\end{array}$ \\
\hline SN & $\begin{array}{c}\text { O bisavô gosta do } \\
\text { pássaro }\end{array}$ & $\begin{array}{c}\text { O pássaro gosta do } \\
\text { Renato }\end{array}$ & $\begin{array}{c}\text { O pássaro gosta do } \\
\text { bisavô }\end{array}$ \\
\hline SA & $\begin{array}{c}\text { O bisavô gosta do } \\
\text { pássaro bêbado }\end{array}$ & $\begin{array}{c}\text { O pássaro gosta do } \\
\text { bisavô pateta }\end{array}$ & $\begin{array}{c}\text { O Renato gosta do } \\
\text { bisavô nadador }\end{array}$ \\
\hline SA & $\begin{array}{c}\text { O Renato gosta do } \\
\text { pássaro bêba }\end{array}$ & $\begin{array}{c}\text { O pássaro gosta do } \\
\text { Renato pateta }\end{array}$ & $\begin{array}{c}\text { O pássaro gosta do } \\
\text { Renato nadador }\end{array}$ \\
\hline SA & $\begin{array}{c}\text { O pássaro gosta do } \\
\text { bisavô bêbado }\end{array}$ & $\begin{array}{c}\text { O Renato gosta do } \\
\text { pássaro pateta }\end{array}$ & $\begin{array}{c}\text { O Renato gosta do } \\
\text { pássaro nadador }\end{array}$ \\
\hline SP & $\begin{array}{c}\text { O pássaro gosta do } \\
\text { Renato de Mônaco }\end{array}$ & $\begin{array}{c}\text { O pássaro gosta do } \\
\text { Renato de Veneza }\end{array}$ & $\begin{array}{c}\text { O pássaro gosta do } \\
\text { Renato de Salvador }\end{array}$ \\
\hline
\end{tabular}

Dessa forma, para a coleta de dados foram aplicados os mesmos procedimentos metodológicos determinados pela coordenação geral do projeto AMPER, a saber: aplicação de um questionário comum de base (QCB) composto de 21 frases a serem produzidas em duas modalidades entoacionais (declarativa neutra e interrogativa total); indução da pronúncia dos 102 enunciados por meio de estímulos visuais para evitar qualquer contato com a forma escrita das frases; repetição aleatória de 6 vezes de cada série de 102 enunciados; gravação realizada na casa do informante.

Uma vez concluído o trabalho de campo, procedemos ao tratamento dos dados obtidos que compreendeu seis etapas: i) codificação dos dados; ii) isolamento das repetições em arquivos de áudio individuais; iii) segmentação dos sinais de áudio no programa PRAAT; iv) aplicação do script amper praat para obtenção das medidas acústicas dos segmentos vocálicos; v) seleção das 3 melhores repetições; vi) aplicação da interface amper para obtenção das médias dos parâmetros físicos controlados - frequência fundamental $(\mathrm{Hz})$, duração (ms) e intensidade (dB) - pelo projeto AMPER, considerando os valores das 3 melhores repetições.

Após a conclusão das seis etapas, procedemos a análise acústica multiparamétrica necessária e fundamental para dar conta dos fenômenos prosódicos. A interface AMPER criada por Albert Rilliard fornece uma análise acústica preliminar dos dados, considerando o comportamento dos três parâmetros físicos controlados na discriminação das modalidades alvo do projeto (declarativa neutra e interrogativa total). 
Ao todo foram 756 dados analisados (21 frases $\times 2$ modalidades $\times 3$ melhores repetições x 6 participantes da pesquisa). Os valores de F0 das curvas entoacionais foram estilizados pelo programa Prosogram (Mertens, 2004), foram utilizados valores de duração relativa das unidades V2V (Barbosa, 2007), em seguida a duração e a intensidade de cada participante da pesquisa foram normalizadas em z-score (Campbell, 1992).

\section{ANÁLISE DE DADOS}

Nesta seção apresentamos a análise dos dados tomando como base as pautas acentuais do português brasileiro - oxítona, paroxítona e proparoxítona.

Demonstramos aqui os parâmetros físicos de F0, duração e intensidade, considerando as variáveis sexo e escolaridade. O objetivo desta análise incide sob a intenção de verificar se há diferenças e semelhanças entre as curvas melódicas das sílabas, em contexto final, de sentenças declarativas e interrogativas.

Os gráficos demonstram os parâmetros prosódicos de F0, duração e intensidade em relação aos falantes do sexo masculino e feminino. Como podemos observar na ilustração a seguir:

Fig. 3: F0, duração e intensidade em relação aos falantes do sexo masculino e feminino.
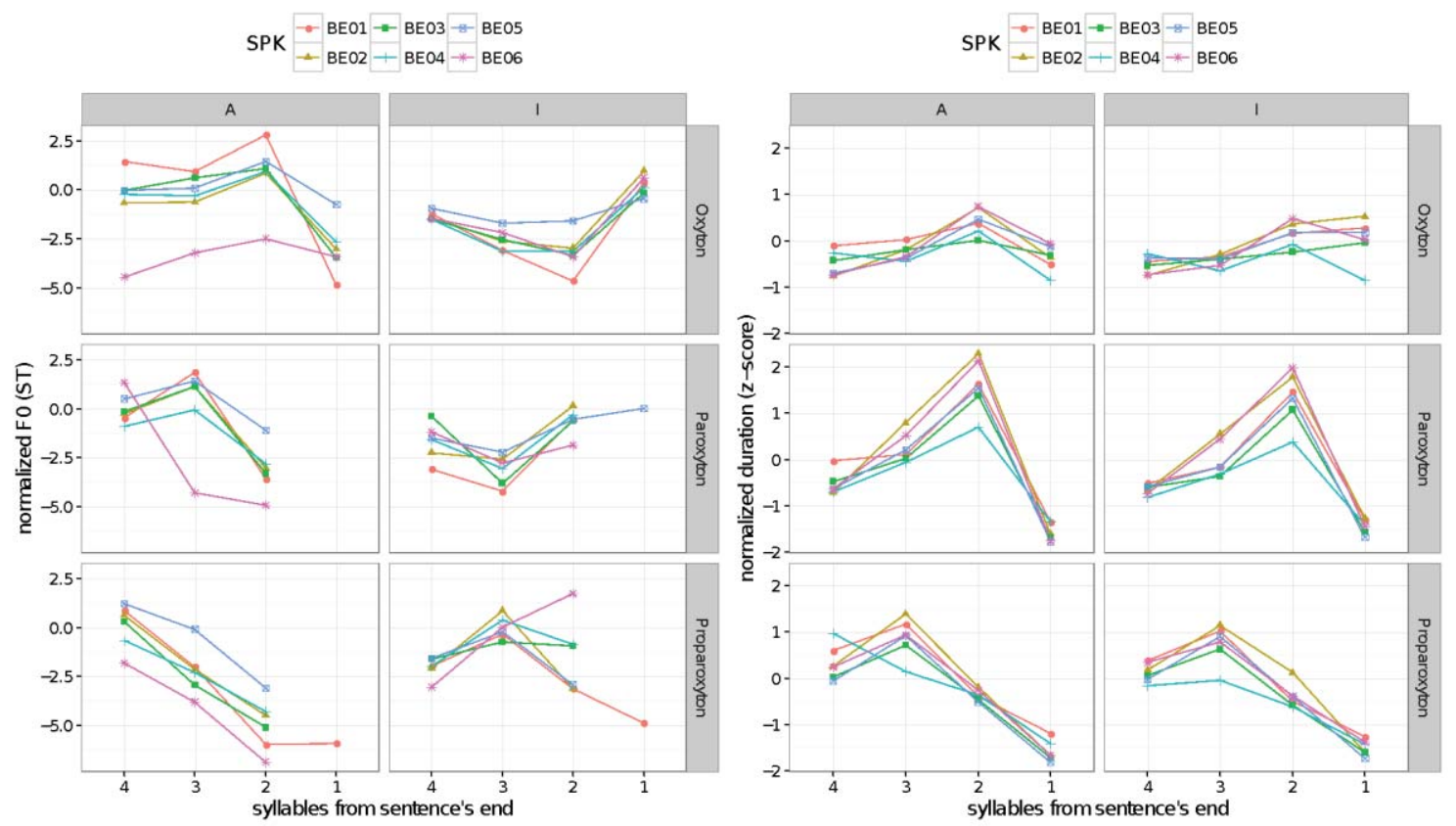

Legenda: Parâmetros de F0 ( $1^{\circ}$ gráfico), parâmetros de duração ( $2^{\circ}$ gráfico), parâmetros de intensidade ( $3^{\circ}$ gráfico). Pauta acentual: oxítona ( $1^{\mathrm{a}}$ linha), paroxítona ( $2^{\mathrm{a}}$ linha), proparoxítona ( $3^{\mathrm{a}}$ linha). Modalidade entoacional declarativa (coluna da esquerda), modalidade entoacional interrogativa (coluna da direita). Cada cor refere-se à um locutor. 
De acordo com os resultados, a F0 é o parâmetro de maior relevância na distinção entre declarativas e interrogativas, apresentando movimentos significativos que ocorrem na sílaba tônica do último vocábulo das sentenças.

Nas sentenças, confirma-se o padrão de distinção melódica entre as modalidades entoacionais. A curva melódica apresenta movimento descendente para as sentenças declarativas e ascendente para as sentenças interrogativas. A localização do acento nos vocábulos representativos define a curvatura melódica. $\mathrm{O}$ cruzamento que acontece entre linhas melódicas na sílaba tônica cria um desenho em formato de pinça.

Nas pautas acentuais, as declarativas apresentam pico entoacional no início da sílaba tônica do vocábulo e a partir desse movimento sofrem queda na tônica, seguindo até as postônicas. As interrogativas apresentam pico entoacional na tônica e ascendência a partir dela, esse comportamento forma o que denominamos de movimento de pinça, padrão também encontrado em outros estudos.

Quanto à duração, os resultados demonstram que, quando comparamos as três pautas acentuais, os locutores, tanto femininos quanto masculinos, fazem a distinção entre a sentença declarativa e interrogativa em vocábulos oxítonos, paroxítonos e proparoxítonos, apresentando medidas de duração maior para a declarativa, quando comparado com a interrogativa, em todas as pautas acentuais.

No que concerne aos gráficos de intensidade, percebe-se que não apresentam informações acústicas relevantes para nos dar suporte necessário na diferenciação das duas modalidades entoacionais. Por isso, o parâmetro intensidade mostra-se irrelevante no que diz respeito à diferenciação entre as sentenças declarativas e interrogativas.

Os próximos gráficos demonstram os parâmetros prosódicos de F0, duração e intensidade por nível de escolaridade. Como podemos observar na ilustração a seguir: 
Fig. 4: F0, duração e intensidade por nível de escolaridade
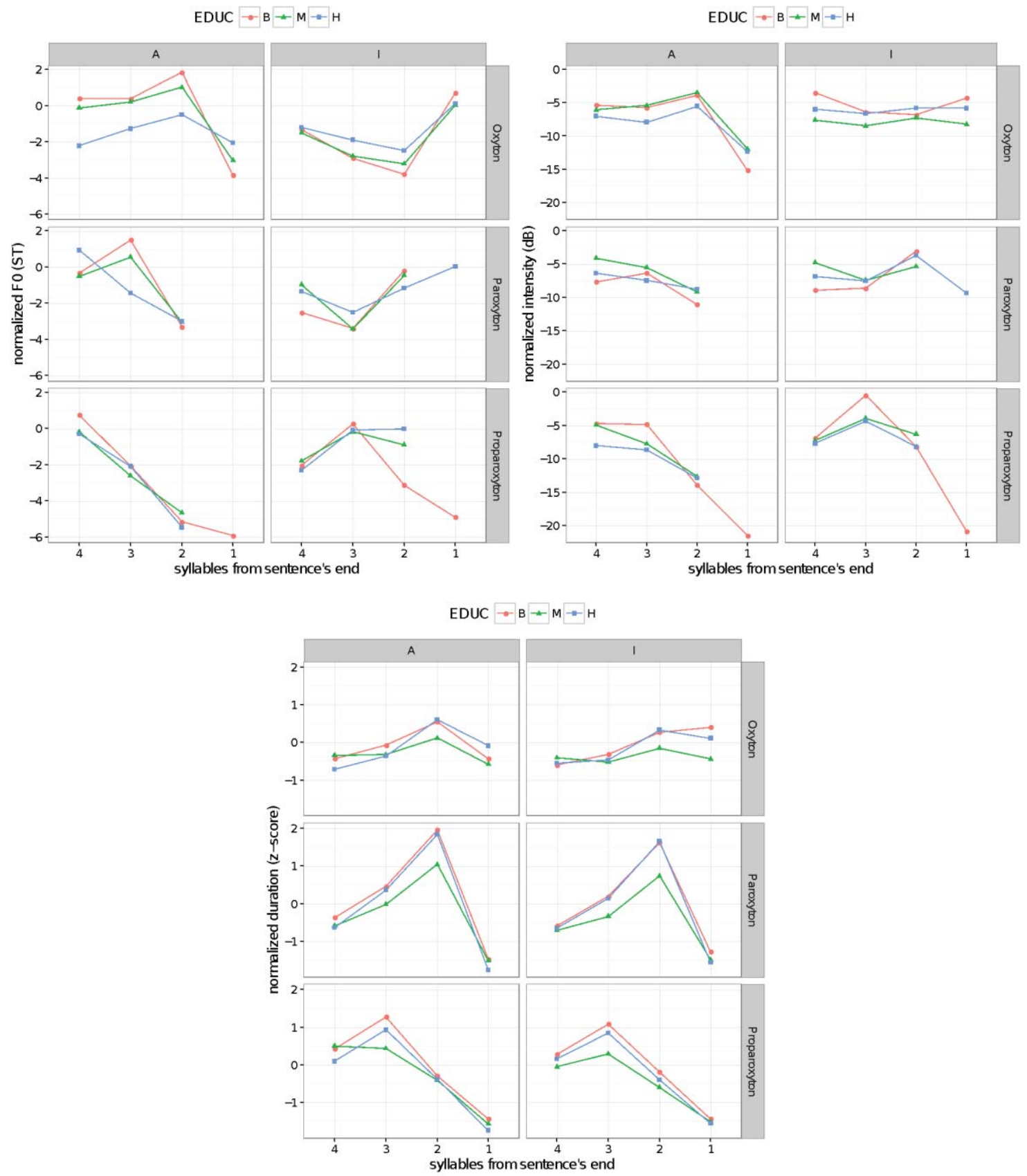

Legenda: Parâmetros de F0 ( $1^{\circ}$ gráfico), parâmetros de duração ( $2^{\circ}$ gráfico), parâmetros de intensidade $\left(3^{\circ}\right.$ gráfico). Pauta acentual: oxítona ( $1^{\mathrm{a}}$ linha), paroxítona ( $2^{\mathrm{a}}$ linha), proparoxítona ( $3^{\mathrm{a}}$ linha). Modalidade entoacional declarativa (coluna da esquerda), modalidade entoacional interrogativa (coluna da direita). Cada cor refere-se à um nível de escolaridade - ensino fundamental (vermelho), ensino médio (verde), ensino superior (azul).

Os resultados de F0 demonstram diferenças entre os falantes de escolaridade mais elevada (nível superior) e os falantes de baixa escolaridade (ensino fundamental) em todas as pautas acentuais. Na pauta acentual proparoxítona, a marcação entoacional entre os níveis de escolaridade é bem evidente, o locutor do ensino fundamental apresenta um padrão prosódico diferente do locutor do ensino superior. Nossas hipóteses acerca desse fator, relacionam-se ao 
grau de escolarização que os sujeitos são submetidos e as situações discursivas em que se inserem.

$\mathrm{Na}$ fala dos belenenses ocorreu a presença do contorno circunflexo final, esse contorno ocorre no interior da sílaba tônica, sendo o pico alinhado à sua direita, tal como no estudo realizado por Moraes (1998) para o português brasileiro.

Os dados de duração corroboram com os dados de F0, evidenciando a diferenciação entre o nível básico e superior. Na pauta acentual proparoxítona, observamos as características apresentadas pelo ensino básico divergindo dos outros níveis de estudo e na pauta acentual paroxítona, modalidade interrogativa, percebemos uma movimentação prosódica diferenciada do falante de nível superior.

Quanto aos dados relativos à intensidade, tais parâmetros mostram-se irrelevantes para caracterização.

No que concerne a posição dos locutores em relação as modalidades entoacionais do corpus, entre todos os pares de frases idênticas, restringindo o contorno da última palavra (as três últimas sílabas). Verifiquemos a figura a seguir:

Fig. 5: Posição dos locutores em relação as modalidades entoacionais do corpus
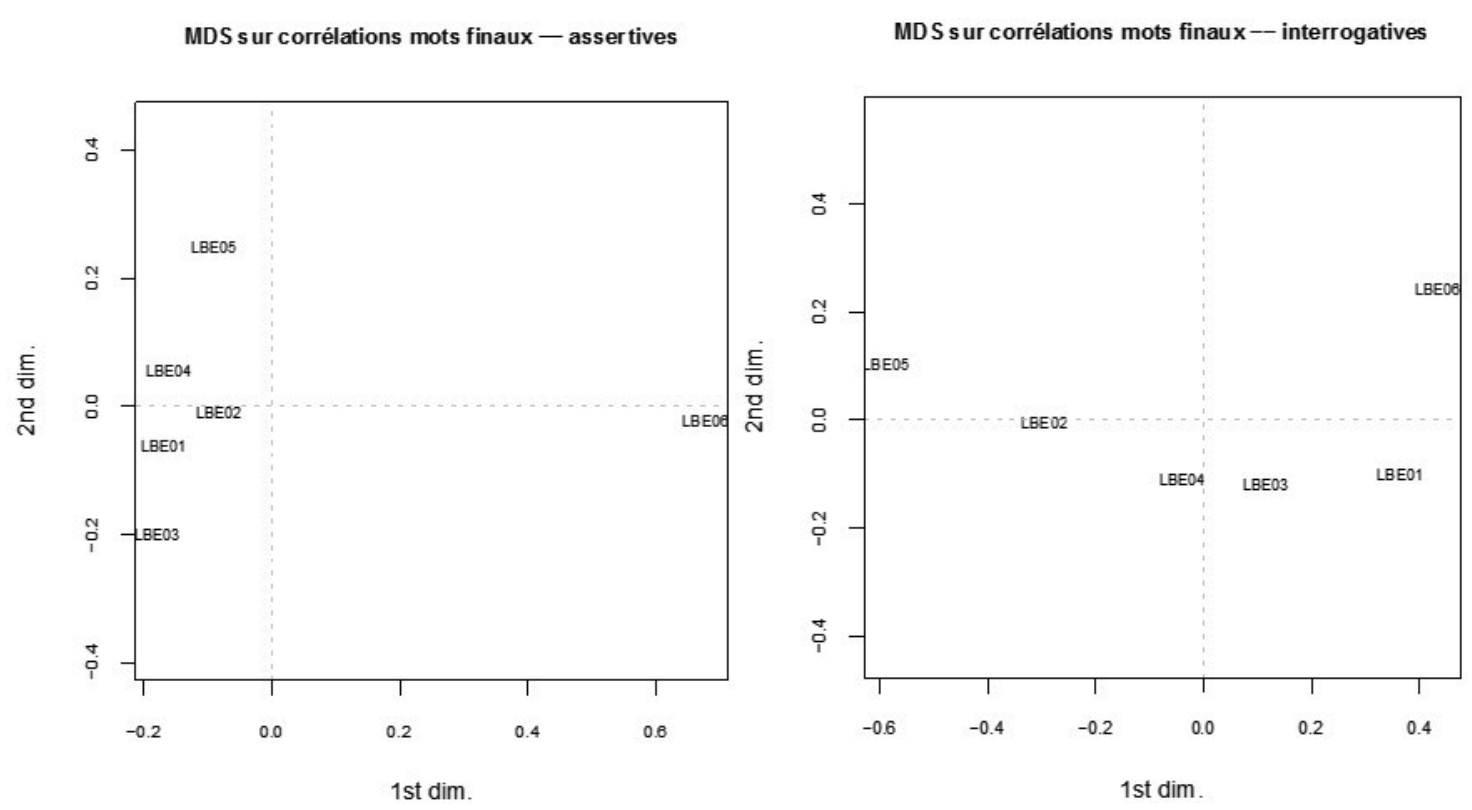

Por meio dos dados, podemos observar que, tanto na modalidade entoacional declarativa quanto na interrogativa, de acordo com o espaço amostral delimitado, o locutor BE06 se distancia prosodicamente dos demais locutores, também apresenta relativa diferença, em menor proporção, o locutor BE05. Com isso, podemos constatar que, quanto maior o nível de escolaridade, o padrão entoacional se diferencia, uma vez que esse fenômeno ocorre na 
produção de fala dos locutores de nível superior.

A tabela a seguir mostra os movimentos melódicos, relativos à última sílaba tônica das sentenças, estilizados pelo Prosogram (Mertens, 2004). Nela consta as percentagens para cada forma realizada na produção de fala de mulheres ou homens, nas modalidades entoacionais declarativa ou interrogativa, para cada tipo de acento (oxítono, paroxítono e proparoxítono).

Tabela 1. Movimentos melódicos estilizados pelo Prosogram

\begin{tabular}{|c|c|c|c|c|c|c|c|c|c|c|c|c|}
\hline \multirow[t]{3}{*}{ Forme } & \multicolumn{6}{|c|}{ Mulher } & \multicolumn{6}{|c|}{ Homem } \\
\hline & \multicolumn{3}{|c|}{ Declarativa } & \multicolumn{3}{|c|}{ Interrogativa } & \multicolumn{3}{|c|}{ Declarativa } & \multicolumn{3}{|c|}{ Interrogativa } \\
\hline & Oxi. & Par. & Pro. & Oxi. & Par. & Pro. & Oxi. & Par. & Pro. & Oxi. & Par. & Pro. \\
\hline 0 & 30 & 29 & 57 & 33 & 65 & 57 & 87 & 60 & 60 & 44 & 76 & 73 \\
\hline - & 56 & 68 & 35 & 11 & 2 & 10 & 13 & 38 & 40 & 3 & 3 & 8 \\
\hline-+ & 8 & 3 & 5 & 0 & 0 & 0 & 0 & 0 & 0 & 0 & 5 & 0 \\
\hline+ & 5 & 0 & 3 & 56 & 32 & 33 & 0 & 2 & 0 & 49 & 14 & 19 \\
\hline+- & 2 & 0 & 0 & 0 & 2 & 0 & 0 & 0 & 0 & 3 & 2 & 0 \\
\hline Total & 100 & 100 & 100 & 100 & 100 & 100 & 100 & 100 & 100 & 100 & 100 & 100 \\
\hline
\end{tabular}

No que concerne a variedade belenense, observamos que os locutores produzem, geralmente, altas taxas de tons dinâmicos. As mulheres tendem a produzir tons dinâmicos mais altos do que os produzidos pelos homens.

$\mathrm{Na}$ modalidade entoacional declarativa, as mulheres produzem tons descendentes em sua maioria, exceto nas proparoxítonas. Os homens, em sua maior parte, produzem tons planos, mas com uma proporção significativa de tons descendentes, especialmente nas proparoxítonas.

$\mathrm{Na}$ modalidade entoacional interrogativa, tanto as mulheres quanto os homens produzem tons dinâmicos em sua maior parte na sílaba tônica, especialmente nas oxítonas. As mulheres produzem alguns tons dinâmicos descendentes nas interrogativas oxítonas.

\section{CONSIDERAÇÕES FINAIS}

Neste estudo, analisamos a fala de seis locutores belenenses, estratificados em sexo e escolaridade. O corpus foi constituído por meio da repetição de 21 frases entoadas nas modalidades declarativa e interrogativa, envolvendo as três pautas acentuais do português oxítona, paroxítona e proparoxítona. Ao todo foram 756 dados analisados (21 frases x 2 modalidades x 3 melhores repetições x 6 participantes da pesquisa).

O enfoque do trabalho consiste em analisar a variação prosódica dialetal do português 
falado em Belém do Pará, observando o contorno entoacional das sentenças declarativas e interrogativas.

A pesquisa seguiu a metodologia proposta pelo projeto AMPER. Os resultados aqui explicitados apontam que a F0 é o fator determinante para a distinção entre as modalidades entoacionais declarativa e interrogativa na variedade em escopo. As variações significativas de F0 ocorrem, preferencialmente, na sílaba tônica do elemento nuclear do sintagma nominal.

A análise comprova que, para F0, a curva melódica no final do enunciado apresenta movimento descendente para as sentenças declarativas e ascendente para as interrogativas, ocorrendo o movimento de pinça.

Os dados relativos à duração, mostram a realização do contorno final circunflexo previsto por Moraes (1998) para o PB, ocorrendo nessa variedade, uma vez que esse contorno ocorre no interior da sílaba tônica.

No que concerne ao grau de escolaridade, o nível superior apresenta distinções prosódicas em relação aos demais níveis de escolaridade. O grau de escolarização que os sujeitos perpassam e as situações discursivas em que se inserem influenciam na constituição do comportamento prosódico.

A fala de Belém apresenta um padrão regular com diferenciação do movimento melódico realizado por homens e mulheres. De modo geral, observamos que os locutores produzem altas taxas de tons dinâmicos, apresentando variações relativas ao movimento de produção de uma declarativa e de uma interrogativa, com diferenças melódicas na pauta acentual.

Tomando como base as considerações expostas, pretendemos contribuir com a investigação do comportamento melódico das sentenças declarativas e interrogativas produzidas pelos belenenses.

A composição desse corpus é uma contribuição para a base de dados do projeto AMPER e uma importante ferramenta para o entendimento, a nível prosódico, de uma das muitas variedades do português faladas no Brasil.

\section{REFERÊNCIAS}

AMPER-POR. Disponível em: 〈http://pfonetica.web.ua.pt/AMPER-POR.htm\#3 >. Acesso em 30 ago. 2016.

BARBOSA, P. A.; MADUREIRA, S. Manual de Fonética Acústica Experimental: Aplicações a dados do português. São Paulo: Cortez, 2015. 
CALVET, L. J. Sociolinguística: uma introdução crítica. São Paulo: Parábola, 2002.

CAMPBELL, N. Syllable-based segmentation. Talking Machine: Theories, models and designs. 1992. p. 211-224.

KENT, R. D.; READ, C. Análise Acústica da Fala. Tradução de Alexsandro Meireles. São Paulo: Cortez, 2015.

LADD, R. Intonational phonology. Cambrige: Cambridge University Press, 1996.

MERTENS, P. The Prosogram: Semi-Automatic Transcription of Prosody based on a Tonal Perception Model. In.: Bernard Bel \& Isabelle Marlien (eds.). Proceedings of Speech Prosody. 2004. Nara (Japan), 2004. p. 23-26.

MORAES, J. Intonation in Brazilian Portuguese. In.: D. Hirst \& A. Di Cristo (eds.). Intonation Systems. A Survey of Twenty Languages. Cambridge: Cambridge University Press, 1998. p. 179-194.

ROACH, P. A little encyclopaedia of phonetics. 2002. Disponível em: <http://www.personal.reading.ac.uk/ llsroach/peter/>. Acesso em: 21 ago. 2016.

SANTO, P.E. Ilma Pinto do. Atlas Prosódico Multimédiado Município de Cametá. Belém: UFPA/ILCS/FALE. Dissertação de Mestrado, 2012. 